\title{
CLINICAL PRACTICE GUIDELINE
}

\section{Unipolar Depression}

\author{
Diagnostic and Therapeutic Recommendations From the Current S3/National \\ Clinical Practice Guideline
}

Martin Härter, Christian Klesse, Isaac Bermejo, Frank Schneider, Mathias Berger

\footnotetext{
Institut und Poliklinik für Medizinische Psychologie, Universitätsklinikum HamburgEppendorf: Prof. Dr. med. Dr. phil. Härter, Dipl.-Psych.

Abteilung für Psychiatrie und Psychotherapie, Universitätsklinikum Freiburg: Dipl.-Psych. Klesse, Dr. phil. Bermejo, Prof. Dr. med. Berger

Klinik für Psychiatrie und Psychotherapie, Universitätsklinikum Aachen: Prof. Dr. med. Dr. rer. soc. Schneider Dipl.-Psych.
}

\section{SUMMARY}

Background: Depressive disorders are among the most common illnesses and reasons for obtaining health care. Their diagnosis and treatment are still in need of improvement. In Germany, a new S3/National Clinical Practice Guideline has been developed for this purpose.

Methods: The existing guidelines on unipolar depression from Germany and other countries were synoptically compared and supplemented with systematic literature searches. After 14 consensus conferences, a total of 107 evidence-based recommendations were issued.

Results: Unipolar depression should be diagnosed in accordance with ICD-10 criteria. Screening questionnaires are useful aids to diagnostic classification. When a treatment is chosen, shared decision-making with the patient is essential. Mild depressive episodes can be treated initially by watchful waiting for 14 days. For moderate depressive episodes, pharmacotherapy and psychotherapy are equally effective treatment options. For severe depression, a combination of pharmacotherapy and psychotherapy is recommended. If 4 to 6 weeks of acute therapy are insufficiently effective, lithium augmentation is recommended, rather than combination antidepressant therapy or a switch to another antidepressant. After remission, maintenance therapy should be continued for 4 to 9 months. In recurrent depression, pharmacotherapy and/ or psychotherapy, where appropriate, should be continued for at least two years. Specific recommendations are given for patients who have somatic or mental comorbidities or are acutely suicidal, and recommendations are also given for coordination of care.

Conclusion: This guideline is a comprehensive set of evidence- and consensus-based recommendations for the diagnosis and treatment of unipolar depression. An improvement in the care of patients with unipolar depression will require broad implementation of the guideline, both in the inpatient and outpatient setting.
Gite this as: Dtsch Arztebl Int 2010; 107(40): 700-8 DOl: 10.3238/arztebl.2010.0700 he importance of unipolar depression as a common and widespread illness is continually increasing. With a lifetime prevalence of $16 \%$ to $20 \%$, depressive disorders range among the most common pathologies and causes for health consultations in Germany (1). Adequate and timely diagnosis of depressive disorders bear great potential for improvements in health services, and an equally promising approach is to base diagnostic evaluation and treatment on evidence-based recommendations, and stepwise and networked or interdisciplinary health care $(2,3)$.

The S3 clinical practice guideline was initiated by the German Association for Psychiatry and Psychotherapy (Deutsche Gesellschaft für Psychiatrie, Psychotherapie und Nervenheilkunde, DGPPN), which presided over the guideline development, its funding, and its preparation, in 2005-2009, in collaboration with other medical societies and with the support of the Association of Scientific Medical Societies in Germany (Arbeitsgemeinschaft der Wissenschaftlichen Medizinischen Fachgesellschaften, AWMF). Further, the guideline was finalized as a German National Clinical Practice Guideline (Nationale VersorgungsLeitlinie, NVL) under the coordination of the German Agency for Quality in Medicine (Ärztliches Zentrum für Qualität in der Medizin, ÄZQ) and $(4,5)$.

\section{Methods}

The consensus group of the S3 guideline consisted of representatives from 29 medical societies and professional associations, as well as self help groups and associations of family members/relatives (eBox 1 and 2). A steering group was formed to develop the clinical practice guideline and coordinate the consensus conferences. This group was consulted for the background texts set out by the coordination team and prepared new suggestions for decisions on this basis $(5,6)$.

Consensus was reached on a total of 107 statements and recommendations in 14 moderated expert meetings. The recommendations are based on the synoptic integration of national and international guidelines on the one hand (eBox 3 ); the central source guideline was the British guideline set out by the National Institute for Health and Clinical Excellence (NICE), entitled "Depression: Management of Depression in Primary and Secondary Care.” Where guideline recommendations did not provide satisfactory answers to the key 
questions or did not fit in with the German healthcare system, systematic literature searches were undertaken, especially for meta-analyses, systematic reviews, and randomized controlled studies.

The recommendations were signed off by the participating experts in a consensus (Figure 1).

\section{Diagnostic evaluation}

This guideline applies to depressive episodes, recurring depressive disorders, dysthymia, and recurrent short depressive disorders in patients of 18 years or older.

Diagnostically, this guideline follows the criteria laid out by the International Classification of Diseases (ICD-10) (Figure 2). Patients can be screened for possible depressive episodes by using the following questions (7):

- In the past month, have you often felt down, sad, worried, or hopeless?

- In the past month, have you felt notably less inclination to pursue, or enjoyment in doing, things that you normally enjoy?

If the screening questions yield raised scores for depression, then a diagnosis of a depressive disorder that requires treatment should be made by immediate direct and complete capture of the main symptoms and additional symptoms (=degree of severity) and questions relating to duration and course (evidence level B; strength of evidence IIb) (Box 1).

Depressed patients rarely report typical depressive symptoms; rather, they will complain about not being able to sleep and waking up early, loss of appetite, general lack of energy, sustained pain, and/or physical symptoms. For this reason, the presence of a depressive disorder or of further symptoms of a depressive disorder should be actively explored (evidence level 0 , strength of evidence III).

In depressive disorders it is important to carefully check for physical diseases, prescribed medications and harmful substances, which may be accompanied by depressive symptoms, and somatic comorbidities. If patients proceed to psychotherapy only, their physical condition should be thoroughly and reliably checked (evidence level 0, strength of evidence III).

In every patient with a depressive disorder, the clinician should assess clinically their suicidality in every encounter and if required explore this further (evidence level clinical consensus point, strength of evidence IV).

Beyond the statutory duty to provide information and in the sense of participatory decision-making, the treating clinician/therapist should talk to the patient about possible treatment strategies and the associated adverse effects and possible risks (advantages and disadvantages of specific therapeutic options) and reach a decision (evidence level B; strength of evidence Ib) (8).

\section{Starting treatment}

The basis for the patients' cooperation, especially when treatment is just starting, is the creation of a stable relationship between therapist and patient, provision of tailored and comprehensible information, and regular
Convening the coordinating team, consensus group, and steering group

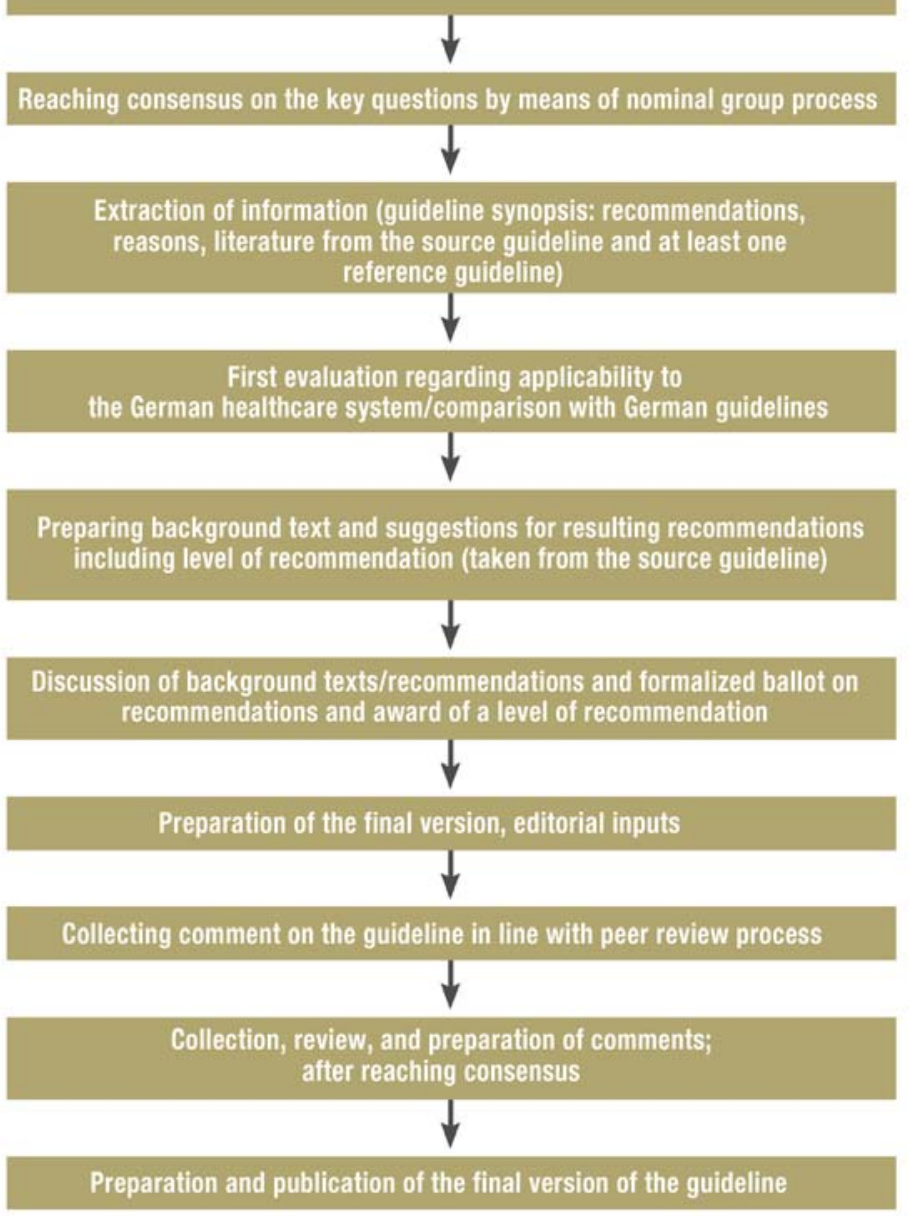

Development process of the German S3/National Clinical Practice Guideline "Unipolar Depression"

information updates. Depressed patients should be informed about the symptoms, disease course, and treatment of depression. Where this is appropriate and the patient agrees, this also applies to their families (evidence level A, strength of evidence IV).

Psychoeducational services for patients and relatives/family members should be provided as a useful add-on in the context of an overall treatment strategy, so as to improve the level of information, acceptance, and the patient's willingness to cooperate (evidence level B, strength of evidence Ib-IIa).

Patients and relatives should receive information about self help groups and family members' groups; they should be encouraged to participate in such groups, if needed (evidence level A, strength of evidence IV).

At the start of antidepressant treatment, the patient should be fully informed about possible adverse effects, the possible latency period, and the duration of 
FIGURE 2

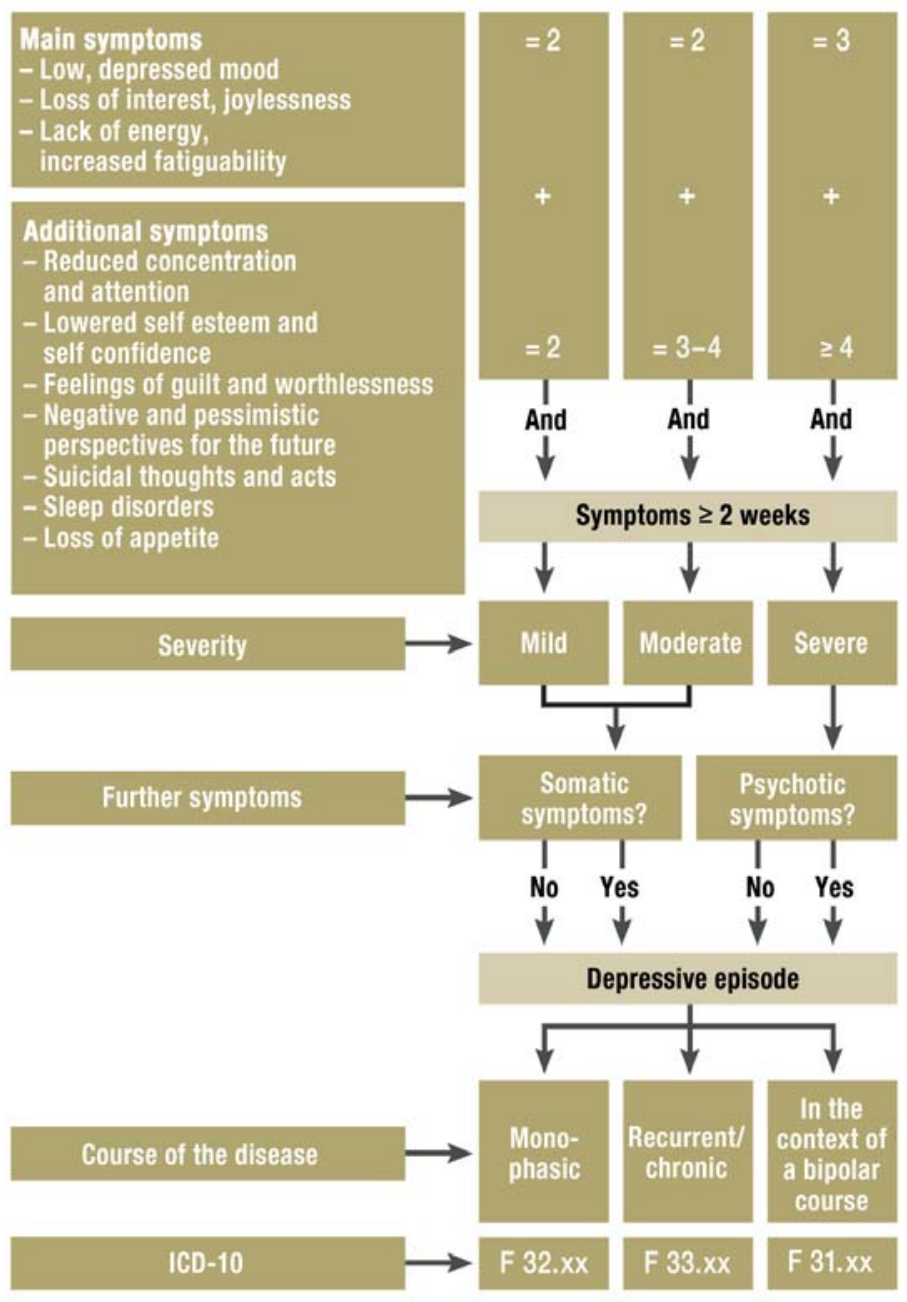

Algorithm for the diagnosis of depressive disorders according to ICD-10

\section{Acute therapy of mild and moderate depressive episodes}

In a mild depressive episode, the efficacy of antidepressants and placebo are not statistically significantly different (9). In moderate to severe depressive episodes, the efficacy of antidepressants is notably greater than that of placebo (10).

Most of the evidence for the efficacy of psychotherapeutic monotherapy applies to mild and moderate depression; cognitive behavioral therapy (CBT), interpersonal psychotherapy (IPT), and short-term psychodynamic therapy (STPP) (11-13) are the approaches that are backed up by the best evidence.

In a mild depressive episode, specific treatment for depression may initially not be necessary-in the sense of active watchful waiting - if it is to be expected that the symptoms will remit without active treatment (Figure 3). If the symptoms persist after a fortnight or have deteriorated then the therapist and patient should discuss starting specific treatment (evidence level 0 , strength of evidence IIb.

Antidepressants should generally not be used for initial treatment of mild depressive episodes, only after critical evaluation of risks versus benefits (evidence level B, strength of evidence Ia).

Antidepressants may be indicated in mild depression in the following scenarios:

- Patient's wishes/preference

- Patient's positive experiences with responsiveness to medication therapy in the past

- Continued symptoms after alternative interventions

- Episodes of moderate or severe depression in the patient's history.

Psychotherapy should be offered to treat mild to moderate depressive episodes (evidence level A, strength of evidence Ia).

Medication therapy with an antidepressant should be offered to treat an acute moderate depressive episode (evidence level A, strength of evidence Ia).

If considering pharmacotherapy for mild to moderate depressive episodes then an initial therapeutic attempt might be made using St John's wort, bearing in mind the herb's specific side effects and interactions (evidence level 0, strength of evidence Ia).

In every patient, antidepressant medication should be started with the lowest, "starter," daily dose.

In older patients, it makes sense to halve the daily starter dose for tricyclic antidepressants and if required step up the dosage gradually (statement, strength of evidence IIb-IV).

\section{Acute treatment for severe depressive episodes}

For severe depressive episodes, the placebo controlled effectiveness of antidepressants and merely CBT or IPT have been confirmed $(10,14)$. The combination of pharmacotherapy and psychotherapy is superior, especially as psychotherapy as the sole treatment modality may well have a longer latency period. In acute 


\section{Evidence level and grades of recommendation}

Strength of evidence

la Evidence from a meta-analysis of at least 3 randomized controlled trials (RCTs)

Ib Evidence from at least one randomized controlled trial or a meta-analysis of less than 3 RCTs

Ila Evidence from at least one methodologically well controlled, non-randomized study

IIb Evidence from at least one methodologically sound, quasi-experimental descriptive study

III Evidence from a methodologically sound, non-experimental observational study, such as a comparative study, correlation study, and case study

IV Evidence from reports of expert committees or expert opinion and/or clinical experience of renowned authorities

Grades of recommendation (evidence level)

A "Must" recommendation: at least one randomized controlled trial of overall good quality and consistency, which relates directly to the respective recommendation and was not extrapolated (evidence levels la and Ib)

B "Should" recommendation: well conducted clinical studies, but not randomized clinical studies, that directly relate to the recommendation (evidence levels II or III), or extrapolation of evidence level I if not directly relevant to the specific question

0 "Can" recommendation: reports of expert groups or expert opinion and/or clinical experiences of renowned authorities (evidence level IV) or extrapolation of evidence levels Ila, Ilb, or III; this classification shows that directly applicable clinical studies of good quality do not exist or were not available

CCP Clinical consensus point: recommended as good clinical practice point reached by consensus and on the basis of the clinical experience of the members of the guideline group as a treatment standard whereby no experimental scientific research is possible or desirable

severe depressive episodes, combination treatment consisting of antidepressant drugs and psychotherapy should be offered (evidence level A, strength of evidence Ib) (15).

If considering monotherapy then patients with acute moderate to severe depressive episodes who can be treated on an outpatient basis should be offered psychotherapy as equivalent to medication monotherapy (evidence level A, strength of evidence Ib).

\section{Treating chronic depressive disorders}

In patients with dysthymia (a subsyndromal depressive disorder persisting for 2 years or longer) and "double depression” (a depressive episode on top of existing dysthymia), then the indication for pharmacotherapy should be considered (evidence level A, strength of evidence Ia) (16). In patients with a chronic (persisting for longer than 2 years) depressive episode, pharmacotherapy should be considered (evidence level B, strength of evidence Ib). In dysthymia, double depression, and chronic depression, the patient should be informed that combination therapy (medication and psychotherapy) is more effective than monotherapy (evidence level A, strength of evidence Ib).

\section{Effectiveness, non-response to therapy, and therapy resistant depressive disorders}

Patients' response to medication or psychotherapeutic treatment requires regular monitoring in the context of the diagnostic evaluation of the course and process - in the first 4 weeks, this means weekly check-ups. After 3 to 4 weeks, the check-ups should be based on patients' symptoms (evidence level A, strength of evidence IV).

If no positive results (in the sense of the intended outcome) are seen 3 to 4 weeks after acute treatment was initiated, the treatment that has not yielded results should not be continued unmodified (evidence level 0, strength of evidence Ib). In non-response to pharmacotherapy, 5 strategies are available in principle:

- Measuring serum concentrations and subsequently adapting the dosage ("therapeutic drug monitoring”)

- Increasing the dosage

- Augmentation by adding another pharmaceutical

- Changing the antidepressant, and/or

- Combination with another pharmaceutical (Figure 4).

For many antidepressants (for example, tricyclic antidepressants [TCA], venlafaxine, tranylcypromin) 


\section{Differential diagnostic evaluation of depression}

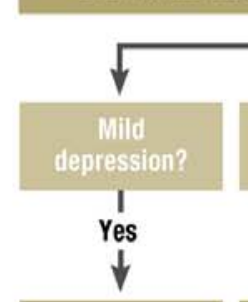

Information/
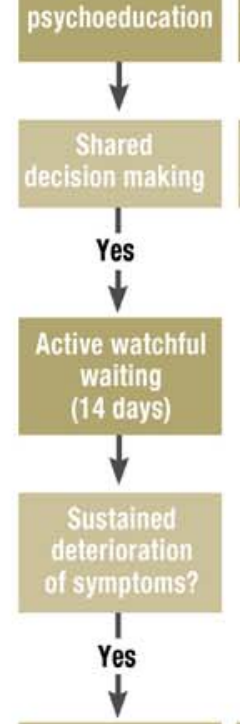

Psychotherapy

or

pharmacotherapy
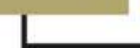

\section{.}

Information/
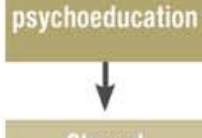

Shared decision making

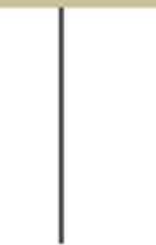

Yes
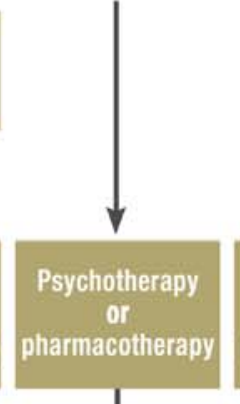
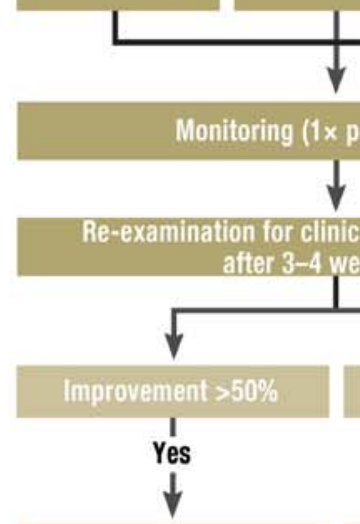

Continuation of treatment

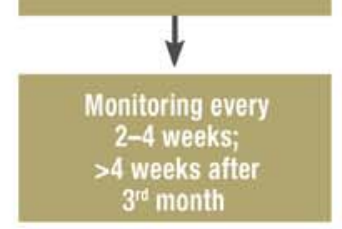

Adjusting treatment (augmentation)

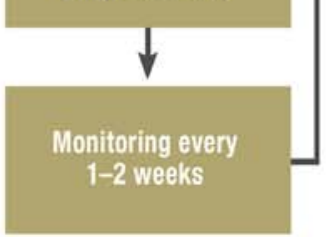

Therapy of depressive disorders

stepping up the dosage is a useful measure in nonresponse, always in accordance with manufacturers' instructions for use. This is not the case for the selective serotonin reuptake inhibitors (SSRIs) (evidence level 0, strength of evidence III).

Experienced doctors should consider attempting augmentation with lithium in patients whose depression has remained unresponsive to antidepressants (evidence level B, strength of evidence Ia) (17). Patients with a good response to an antidepressant and augmentation with lithium should remain on this regimen for at least 6 months (evidence level $\mathrm{B}$, strength of evidence Ia-Ib). If a patient shows no effect 2 to 4 weeks after an effective lithium concentration has been reached then the lithium should be phased out (evidence level clinical consensus point, strength of evidence IIb).

Changing the antidepressant is not a first choice option in the treatment of non-responders. Each change should therefore be carefully weighed (evidence level $\mathrm{B}$, strength of evidence Ib).

For patients who have not responded to antidepressant monotherapy, the only combination treatment that is recommended is mianserin (while bearing in mind the risk of agranulocytosis) or mirtazapine with an SSRI or TCA.

In therapy resistant depression (where pharmacotherapy has been administered adequately, with at least two drugs, one after the other, at a sufficiently high dosage and given for a long enough time interval), patients should be offered appropriate psychotherapy (evidence level B, strength of evidence Ia).

\section{Maintenance treatment and preventing recurrences}

Antidepressants should be taken for a minimum of 4 to 9 months after the remission of a depressive episode; the risk of a recurrence is lowered substantially in this way. In this maintenance phase, the same dosage should be administered as in the acute phase (evidence level A, strength of evidence Ia) (18).

Patients with one or more depressive episodes with important functional impairments in the recent past should be instructed to take the antidepressant for at least 2 years as long-term prophylaxis (evidence level $\mathrm{B}$, strength of evidence $\mathrm{Ib}$ ). To prevent a recurrence, the antidepressant should be given at the same dosage that was effective during the acute phase (evidence level B, strength of evidence Ib). In patients at risk of suicide, medication with lithium should be considered as prophylactic treatment for a recurrence, in order to reduce suicidal acts (suicide attempts and suicide) (evidence level A, strength of evidence Ia) (19).

To stabilize the therapeutic success and lower the risk of recurrence, appropriate psychotherapeutic treatment (maintenance treatment) should be offered after the acute treatment (evidence level A, strength of evidence Ia) (20). In the longer term, stabilizing psychotherapy (prevention of recurrence) should be offered to patients with a raised risk of recurrence (evidence level A, strength of evidence Ia). 


\section{Red flags}

The guideline also focuses on situations where a procedure or a measure used thus far is not to be continued or may be particularly critical:

- After 3 to 4 weeks of unsuccessful, guidelineconform pharmacotherapy, the therapeutic approach should be reconsidered (after 6 weeks in elderly patients)

- After 6 weeks of unsuccessful treatment by a general practitioner, referral to a specialist should be instigated

- After 3 months of unsuccessful psychotherapy, referral to a specialist should be instigated

- Re-examination of patients who were treated as inpatients for suicidal behavior after a maximum of 1 week (direct contact should be sought if the patient does not keep the appointment!).

\section{Pharmacotherapy in particular groups of patients}

In elderly patients, treatment with a tricyclic antidepressant should be started with a lowered initial dose (statement, strength of evidence IIb-III). Compared with younger patients, greater attention needs to be paid to the side effect profile and tolerability of antidepressants.

In patients with depression and organic brain disorders, substances with a sedative and/or anticholinergic effect should be avoided (evidence level 0 , strength of evidence Ib) (21). In patients with psychotic depression, the combination of the antidepressant with an antipsychotic should be considered, although the optimal dosage and length of use of these medications are not known (evidence level B, strength of evidence III).

In coronary heart disease and comorbid moderate to severe depressive disorder, pharmacotherapy should include preferably sertraline or citalopram (evidence level A, strength of evidence Ia). Patients with depression after stroke should be offered pharmacotherapy while bearing in mind the risks of anticholinergic side effects (empirical clues exist for fluoxetine, citalopram, and nortriptylin) (evidence level B, strength of evidence Ib).

In moderate to severe depression with comorbid tumor disease, pharmacotherapy with an antidepressant-especially one of the SSRIs-may be offered (evidence level 0, strength of evidence Ib).

In pharmacotherapy for depression in patients with comorbid diabetes, substance specific effects on the diabetes need to be given attention-for example, the reduced insulin requirement in SSRIs and weight gain with mirtazapine, mianserin, and sedating tricyclic antidepressants (evidence level B, strength of evidence Ib-IIb).

\section{Further somatic treatment options}

Electroconvulsive therapy should be considered in cases of severe, treatment resistant, depressive episodes as a treatment alternative (evidence level A, strength of evidence Ia). Electroconvulsive therapy can also be administered as maintenance treatment in patients who

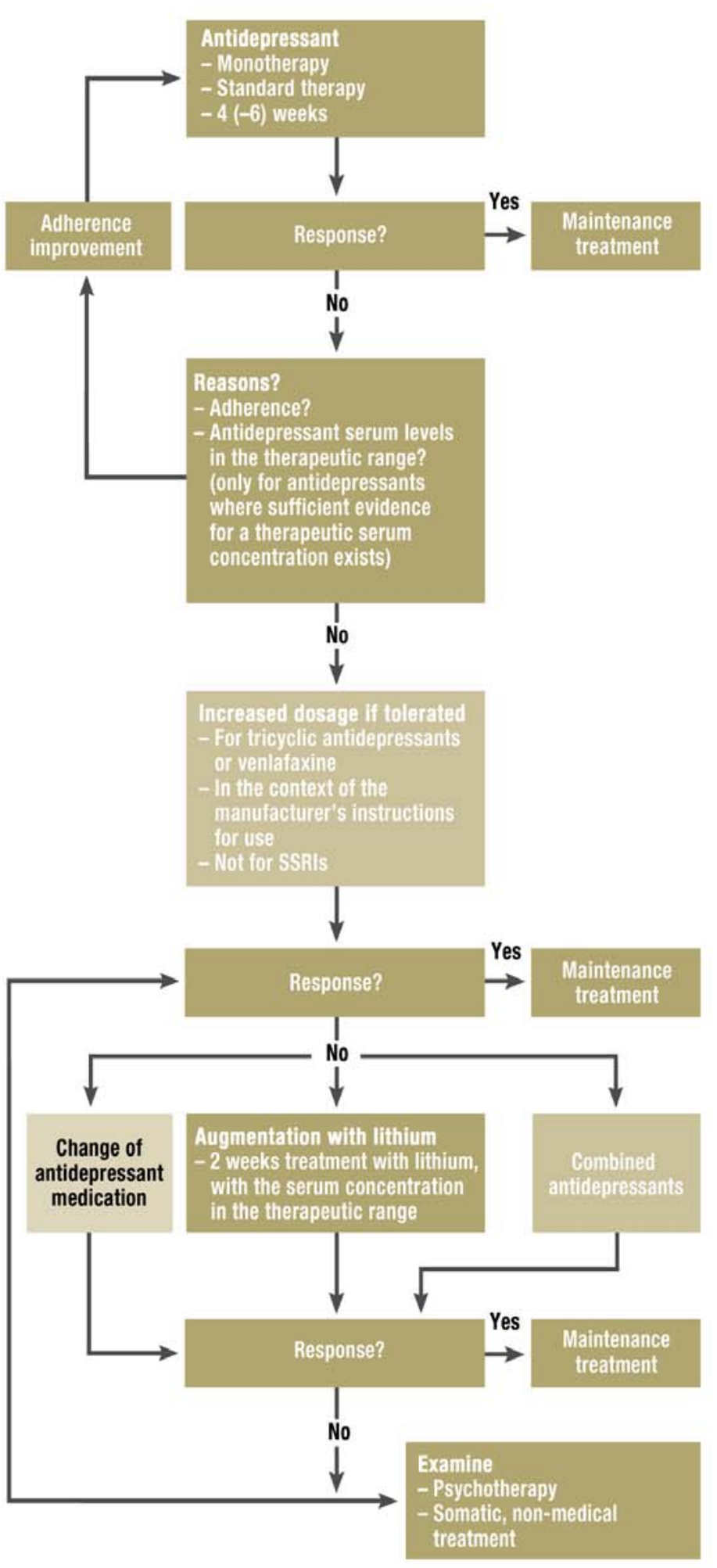

Evidence level 1

Evidence Ievel 2

Evidence level 3 


\section{Intersections in healthcare services (the definition of responsibility corresponds to the clinical consensus of the experts participating in signing off the guideline)}

\section{Outpatient treatment}

In patients with mild to moderate depressive disorders, outpatient treatment can be delivered as the only treatment by all relevant groups-by general practitioners, psychiatrists or psychotherapists, specialists in psychosomatic medicine and psychotherapy, or psychiatrist/neurologists (he/she had 3 years of residence, in both fields), doctors with additional qualifications in psychotherapy or psychoanalysis or psychological psychotherapists. Further, the guideline provides additional indication criteria:

- Treatment by a specialist (psychiatrist/psychotherapist or psychiatrist/neurologist) is indicated particularly in:

- Unclear (differential) diagnostic evaluation of mental disorders

- Severe symptoms

- Resistance to therapy

- Problems with pharmacotherapy and/or psychotherapy

- Problems with interaction in the context of combination therapy of antidepressants with other medications

- Acute risk to self or others

- Psychotic symptoms or depressive stupor

- Comorbidity of a depressive disorder with another severe mental disorder and/or other severe physical disorders.

- Treatment by psychological psychotherapists and specialists in psychosomatic medicine and psychotherapy (in general such experts administer guideline-conform psychotherapy): a referral to these specialists is also recommended in the following scenarios:

- For psychotherapeutic co-treatment in severe symptoms in the context of combination therapy

- In psychotherapeutically accessible resistance to therapy

- In depressive disorders with another comorbid severe mental disorder

- For psychotherapeutic treatment in comorbid depression and chronic physical disorders

- For the purposes of psychotherapeutic (co-)treatment

- When problems arise with psychotherapy.

Inpatient treatment

- The indication for admission to inpatient psychiatric-psychotherapeutic therapy exists in:

- Acute suicidality (emergency indication), or

- Risk of depression related isolation and other severe psychosocial factors

- Circumstances of living that massively hinder therapeutic success

- Therapy resistance to further outpatient treatments and such severe symptoms that outpatient therapeutic options are not sufficient, and

- Strong risk of (further) chronification.

- If in such cases psychotherapy is the treatment of choice, an indication for psychosomatic-psychotherapeutic inpatient treatment may also exist.

- An indication for inpatient rehabilitation treatment exists in particular if the therapeutic aims are strengthening the effects of successful treatment, treating sequelae of the illness, improving the patient's way of dealing with the (chronic or chronified) disorder or restoring or regaining the ability to pursue gainful employment.

- have responded to electroconvulsive therapy during an episode of illness previously,

- have not responded to any other guidelineconform antidepressant treatment,

- have psychotic symptoms, or

- express a preference for this treatment option (evidence level 0, strength of evidence IIa).

Sleep deprivation should be considered to treat depressive episodes if a rapid, albeit not long lasting, response is the therapeutic aim or if the intention is to complement another guideline-conform therapeutic option (evidence level B, strength of evidence Ib). Light therapy should be considered as a treatment option in patients with mild to moderate episodes or recurrent depressive disorders that follow a seasonal pattern (evidence level A, strength of evidence Ia). Exercise can be recommended based on clinical experience, in order to increase the sense of wellbeing and ameliorate depressive symptoms (evidence level clinical consensus point, strength of evidence Ib).

\section{Intersections in healthcare services and outlook}

Box 2 shows numerous examples of intersecting healthcare services for depressed patients (no recommendations in the narrower sense, particularly because 
studies of the transition between the treatment steps are lacking or are difficult to implement [22, 23]). From the recommendations of this guideline, potential quality indicators have been formulated for the purposes of quality assurance, which are of relevance to healthcare services and clinical practice. These, as well as the benefits of implementing the guideline, should be scientifically evaluated in innovative healthcare models or model projects under conditions of outpatient as well as inpatient practice.

Guidelines are subject to dynamic development and require continuous updating. The steering group of this guideline has collected several subject areas that are receiving priority attention for the new edition 2013 ("gender and sex specific aspects", "pregnancy and breast feeding”, "patients from a migrant background”, and "unipolar depression in children and adolescents"). With regard to the psychotherapeutic approaches, an evaluation of the evidence for systemic therapy is planned.

\author{
Acknowledgements \\ The authors of this article thank the following for their extraordinary commit- \\ ment, patience, help in organizing expert meetings, moderation, and contribu- \\ tions to discussions, all of which have all made a vital contribution to the suc- \\ cess in finalizing this guideline: \\ Professor Dr. Ina Kopp (AWMF), moderation of the consensus meeting for the \\ S3 clinical practice guideline "unipolar depression." \\ Dr. med. Susanne Weinbrenner, Dr. med. Berit Meyerrose (both German Agency \\ for Quality in Medicine, Berlin) und Dr. med. Monika Lelgemann (German \\ Agency for Quality in Medicine, Berlin, and Medizinischer Dienst des Spitzen- \\ verbandes Bund der Krankenkassen [MDS, the medical service of the head \\ organization of the German Federal Association of Statutory Health Insurance \\ Funds], consistent support of the coordinating and editing team of the \\ S3-/German Clinical Practice guideline "Unipolar Depression" \\ Professor Dr. Dr. med. Günter Ollenschläger (German Agency for Quality in \\ Medicine), who is responsible for the guideline program of the German Medi- \\ cal Association, the National Association of Statutory Health Insurance Phy- \\ sicians, and the Association of Scientific Medical Societies in Germany \\ (AWMF), moderation of the German Clinical Practice Guideline steering group \\ "Unipolar Depression". The authors also thank the other members of the \\ steering group for contributing their expertise and their readiness to discuss \\ matters (in alphabetical orders): \\ Angela Bleckmann (BApK) \\ PD Dr. med. Tom Bschor (AkdÄ) \\ Prof. Dr. med. Dipl.-Päd. Jochen Gensichen MPH (DEGAM) \\ Dipl.-Psych. Timo Harfst (BPtK) \\ Prof. Dr. phil. Martin Hautzinger (DGPs) \\ Carsten Kolada (BApK) \\ Prof. Dr. sc. hum. Christine Kühner (DGPs) \\ Dipl.-Psych. Jürgen Matzat (DAG SHG) \\ Prof. Dr. med. Christoph Mundt (DGPPN) \\ Prof. Dr. med. Wilhelm Niebling (DEGAM) \\ Prof. Dr. phil. Rainer Richter (BPtK; als Gast) \\ Prof. Dr. med. Henning Schauenburg (DGPM) \\ PD Dr. phil. Holger Schulz (DGRW)
}

\begin{abstract}
Conflict of interest statement
Martin Härter received honoraria for speaking from Lilly and BoehringerIngelheim in 2008.

Isaac Bermejo received honoraria for speaking from Boehringer-Ingelheim and Wyeth Pharma until 2008.

Frank Schneider received until 2008 honoraria for speaking and participation in external advisory boards from AstraZeneca, Janssen-Cilag, Otsouka, and Wyeth. He has received study funding from AstraZeneca and Lilly.

The remaining authors declare that no conflict of interest exists according to the guidelines of the International Committee of Medical Journal Editors.
\end{abstract}

Manuscript received on 26 July 2010, revised version accepted on 26 July 2010.

Translated from the original German by Dr. Birte Twisselmann.

\section{REFERENCES}

1. Jacobi F, Wittchen HU, Hölting C, et al.: Prevalence, co-morbidity and correlates of mental disoders in the general population: results from the German Health Interview and Examination Survey (GHS). Psychol Med 2004; 34: 597-611.

2. Wittchen HU, Müller N, Schmidtkunz B, et al.: Erscheinungsformen, Häufigkeiten und Versorgung von Depressionen. Ergebnisse des bundesweiten Zusatzsurveys „Psychische Störungen“. Fortschr Med [Suppl I] 2000; 118: 4-10.

3. Schneider F, Dausend S, Bermejo I, et al.: Insufficient depression treatment in outpatient settings. German Med Sci 2004; 2: Doc01 (20040226).

4. Härter M, Klesse C, Bermejo I, et al.: Entwicklung der S3- und Nationalen VersorgungsLeitlinie Depression. Bundesgesundheitsbl Gesundheitsforsch Gesundheitsschutz 2008; 51(4): 451-7.

5. Klesse C, Berger M, Bermejo I, et al.: Evidenzbasierte Psychotherapie der Depression - Therapiepraxis nach der aktuellen S3-/Nationalen VersorgungsLeitlinie „Unipolare Depression“ Psychotherapeut 2010; 55: 247-63.

6. DGPPN, BÄK, KBV, AWMF, AkdÄ, BPtK, BApK, DAGSHG, DEGAM, DGPM, DGPs, DGRW (eds.) für die Leitliniengruppe Unipolare Depression: S3-Leitlinie/Nationale VersorgungsLeitlinie Unipolare Depression. 1. Auflage 2009. DGPPN, ÄZQ, AWMF - Berlin, Düsseldorf 2009. Internet: www.dgppn.de, www.versorgungsleitlinien.de, www.awmf-leitlinien.de.

7. Whooley MA, Avins AL, Miranda J, Browner WS: Case-finding instruments for depression. Two questions are as good as many. J Gen Intern Med 1997; 12(7): 439-45.

8. Loh A, Kremer N, Giersdorf N, Jahn H, Hänselmann S, Bermejo I, Härter M: Informations- und Partizipationsinteressen depressiver Patienten bei der medizinischen Entscheidungsfindung in der hausärztlichen Versorgung. Z Arztl Fortbild Qualitatssich 2004; 98(2): 101-7.

9. Kirsch I, Deacon BJ, Huedo-Medina TB, Scoboria A, Moore TJ, Johnson BT: Initial severity and antidepressant benefits: a metaanalysis of data submitted to the Food and Drug Administration. PLoS Med 2008; 5(2): e45.

10. Khan A, Leventhal RM, Khan SR, Brown WA: Severity of depression and response to antidepressants and placebo: an analysis of the Food and Drug Administration database. J Clin Psychopharmacol 2002; 22(1): 40-5.

11. Gloaguen V, Cottraux J, Cucherat M, Blackburn IM: A meta-analysis of the effects of cognitive therapy in depressed patients. J Affect Disord 1998; 49(1): 59-72.

12. Feijo de Mello M, de Jesus Mari J, Bacaltchuk J, Verdeli H, Neugebauer R: A systematic review of research findings on the efficacy of interpersonal therapy for depressive disorders. Eur Arch Psychiatry Clin Neurosci 2004; 255(2): 75.

13. Abbass AA, Hancock JT, Henderson J, Kisely S: Short-term psychodynamic psychotherapies for common mental disorders. Cochrane Database Syst Rev 2006; (4): CD004687.

14. DeRubeis RJ, Gelfand LA, Tang TZ, Simons AD: Medications versus cognitive behavior therapy for severely depressed outpatients: mega-analysis of four randomized comparisons. Am J Psychiatry 1999; 156(7): 1007-13.

15. Thase ME, Greenhouse JB, Frank E, et al.: Treatment of major depression with psychotherapy or psychotherapy-psychopharmacotherapy combinations. Arch Gen Psychiatry 1997; 54(11): 1009-15.

16. Lima MS, Moncrieff J: Drugs versus placebo for dysthymia. Cochrane Database Syst Rev 2000; (4): CD001130.

17. Bauer M, Dopfmer S: Lithium augmentation in treatment-resistant depression: meta-analysis of placebo-controlled studies. J Clin Psychopharmacol 1999; 19(5): 427-34.

18. Geddes JR, Carney SM, Davies C, et al.: Relapse prevention with antidepressant drug treatment in depressive disorders: a systematic review. Lancet 2003; 361(9358): 653-61. 
19. Cipriani A, Pretty H, Hawton K, Geddes JR: Lithium in the prevention of suicidal behavior and all-cause mortality in patients with mood disorders: a systematic review of randomized trials. Am J Psychiatry 2005; 162(10): 1805-19.

20. Vittengl JR, Clark LA, Dunn TW, Jarrett RB: Reducing relapse and recurrence in unipolar depression: a comparative meta-analysis of cognitive-behavioral therapy's effects. J Consult Clin Psychol 2007; 75(3): 475-88.

21. Bains J, Birks JS, Dening TR: The efficacy of antidepressants in the treatment of depression in dementia. Cochrane Database Syst Rev 2002; (4): CD003944.

22. Klesse C, Bermejo I, Härter M: Neue Versorgungsmodelle in der Depressionsbehandlung. CME Weiterbildung - Zertifizierte Fortbildung. Nervenarzt 2007; 78(Suppl 3): 585-95.

23. Härter M, Bermejo I, Ollenschläger G, et al.: Improving quality of care for depression - the German Action Programme for the implementation of evidence-based guidelines. Int J Qual Health Care 2006; 18(2): 113-9.

\section{Corresponding author}

Prof. Dr. med. Dr. phil. Martin Härter, Dipl.-Psych.

Universitätsklinikum Hamburg-Eppendorf

Institut und Poliklinik für Medizinische Psychologie

Martinistr.52 (W 26), 20246 Hamburg, Germany

m.haerter@uke.de 


\title{
CLINICAL PRACTICE GUIDELINE
}

\section{Unipolar Depression}

\author{
Diagnostic and Therapeutic Recommendations From the Current S3/National \\ Clinical Practice Guideline
}

Martin Härter, Christian Klesse, Isaac Bermejo, Frank Schneider, Mathias Berger

Participating medical societies, professional associations, organizations for family and relatives, and self help organizations

- German Association for Psychiatry and Psychotherapy (Deutsche Gesellschaft für Psychiatrie, Psychotherapie und Nervenheilkunde, DGPPN)

- Drug Commission of the German Medical Association (Arzneimittelkommission der deutschen Ärzteschaft, AkdÄ)

- Federal Chamber of Psychotherapists in Germany (advisory) (Bundespsychotherapeutenkammer, BPtK)

- German association for the relatives of people with mental health problems (Bundesverband der Angehörigen psychisch Kranker, BApK)

- German Working Group for Self-help Groups (Deutsche Arbeitsgemeinschaft Selbsthilfegruppen, DAGSHG)

- German College of General Practitioners and Family Physicians (Deutsche Gesellschaft für Allgemeinmedizin und Familienmedizin, DEGAM)

- German Society of Psychosomatic Medicine and Medical Psychotherapy (Deutsche Gesellschaft für Psychosomatische Medizin und Ärztliche Psychotherapie, DGPM)

- German Psychological Society (Deutsche Gesellschaft für Psychologie, DGPS)

- German Society for Rehabilitation Sciences (Deutsche Gesellschaft für Rehabilitationswissenschaften, DGRW)

- Federal Conference of Clinical Directors of Psychiatric Hospitals (and working group for depression wards) (Bundesdirektorenkonferenz psychiatrischer Krankenhäuser [und Arbeitskreis Depressionsstationen], BDK)

- Working group of Clinical Directors of Hospitals for Psychiatry and Psychotherapy at General Hospitals in Germany (Arbeitskreis der Chefärztinnen und Chefärzte von Kliniken für Psychiatrie und Psychotherapie an Allgemeinkrankenhäusern in Deutschland, ACKPA)

- Association of German Professional Psychologists (Berufsverband Deutscher Psychologinnen und Psychologen, BDP)

- Professional Association of Specialists in Psychosomatic Medicine and Psychotherapy in Germany (Berufsverband der Fachärzte für Psychosomatische Medizin und Psychotherapie Deutschlands, BPM)

- Professional Association of German Psychiatrists/Neurologists (Berufsverband Deutscher Nervenärzte, BVDN)

- Professional Association of German Psychiatrists (Berufsverband Deutscher Psychiater, BVDP)

- German Federal Association of Contract Psychotherapists (Bundesverband der Vertragspsychotherapeuten, bvvp)

- Conference of Medical Directors of Psychosomatic-psychotherapeutic Hospitals and Departments (Chefarztkonferenz psychosomatisch-psychotherapeutischer Krankenhäuser und Abteilungen, CPKA)

- German Medical Society of Behavior Therapy (Deutsche Ärztliche Gesellschaft für Verhaltenstherapie, DÄVT)

- German Association for Psychodynamic Psychotherapy (Deutsche Fachgesellschaft für tiefenpsychologisch fundierte Psychotherapie, DFT)

- German Society of Geronto-Psychiatry and Psychotherapy (Deutsche Gesellschaft für Gerontopsychiatrie und -psychotherapie, DGGPP)

- German Society for Psychoanalysis, Psychotherapy, Psychosomatic medicine, and Psychoanalytic Psychology (Deutsche Gesellschaft für Psychoanalyse, Psychotherapie, Psychosomatik und Tiefenpsychologie, DGPT)

- German Society for Behavior Therapy (Deutsche Gesellschaft für Verhaltenstherapie, DGVT)

- German Psychoanalytical Society (Deutsche Psychoanalytische Gesellschaft, DPG)

- German Psychoanalytical Association (Deutsche Psychoanalytische Vereinigung, DPV)

- German Association of Psychotherapists (Deutsche Psychotherapeutenvereinigung, DPtV)

- German Professional Association for Behaviour Therapy (Deutscher Fachverband für Verhaltenstherapie, DVT)

- German Association of General Practitioners (Deutscher Hausärzteverband, BDA)

- German Society for Scientific Person-Centred Psychotherapy (Gesellschaft für wissenschaftliche Gesprächspsychotherapie, GwG)

- Competence Network Depression, Suicidality (Kompetenznetz Depression, Suizidalität, KND) 


\section{Participating experts}

- Members of the guideline steering group

- Angela Bleckmann (BApK)

- PD Dr. med. Tom Bschor (AkdÄ)

- Prof. Dr. med. Dipl.-Päd. Jochen Gensichen MPH (DEGAM)

- Dipl.-Psych. Timo Harfst (BPtK)

- Prof. Dr. phil. Martin Hautzinger (DGPS)

- Carsten Kolada (BApK)

- Prof. Dr. sc. hum. Christine Kühner (DGPS)

- Dipl.-Psych. Jürgen Matzat (DAG SHG)

- Prof. Dr. med. Christoph Mundt (DGPPN)

- Prof. Dr. med. Wilhelm Niebling (DEGAM)

- Prof. Dr. phil. Rainer Richter (BPtK)

- Prof. Dr. med. Henning Schauenburg (DGPM)

- Prof. Dr. med. Dr. rer. soc. Frank Schneider (DGPPN)

- PD Dr. phil. Holger Schulz (DGRW)

- Members of the consensus group

- Prof. Dr. med. Georg Adler (DGGPP)

- PD Dr. med. Lothar Adler (BDK)

- Dr. med. Karin Bell (BPM)

- Dr. med. Frank Bergmann (BVDN)

- Prof. Dr. med. Heinz Böker (DPV)

- Dr. med. Jobst Finke (GwG)

- Prof. Dr. med. Matthias Franz (DPG)

- Dipl.-Psych. Detlev Haimerl (GwG)

- Dr. med. Norbert Hartkamp (DPG)

- Dr. med. Iris Hauth (BDK)

- Prof. Dr. med. Ulrich Hegerl (KND)

- Prof. Dr. phil. Thomas Heidenreich (DGVT)

- Dr. med. Gerhard Hildenbrand (CKPA)

- Dr. med. Wolfram Keller (DGPT)

- Prof. Dr. med. Joachim Küchenhoff (DPV)

- Dipl.-Psych. Christa Leiendecker (DGPT)

- Prof. Dr. med. Hans-Jürgen Luderer (GwG)

- Dr. med. Herbert Menzel (BPM)

- Dr. med. Wolfgang Merkle (CKPA)

- Dipl.-Psych. Rudi Merod (DGVT)

- Dr. med. Norbert Mönter (BVDN)

- Dipl.-Psych. Inge Neiser (BDP)

- Dr. phil. Annelie Scharfenstein (DPtV)

- Prof. Dr. med. Ulrich Schweiger (DVT)

- Dr. med. Regine Simon (BVVP)

- Prof. Dr. med. Gabriela Stoppe (DGGPP)

- Dr. med. Diethard Sturm (BDA)

- PD Dr. rer. soc. Karin Tritt (DFT)

- Dr. med. Hans-Peter Unger (ACKPA)

- Dr. med. Christian P. Vogel (BVDP)

- Dipl.-Psych. Benedikt Waldherr (BVVP)

- Prof. Dr. med. Georg Wiedemann (DÄVT)

- Dr. med. Tobias Wiehn (DÄVT)

- Prof. Dr. med. Dr. h.c. Manfred Wolfersdorf (BDK) 


\section{National and international guidelines that were used as the evidence base}

\section{- Source guideline}

- National Collaborating Centre for Mental Health, National Institute for Clinical Excellence (NICE). Depression: Management of depression in primary and secondary care. Clinical Guideline 23. 2004 [cited: 2006 May 22]. http://www.nice.org. uk/page.aspx?o=235213

\section{- Reference guidelines}

- American Psychiatric Association (APA): Practice guideline for the treatment of patients with major depressive disorder. In: American Psychiatric Association (APA) (ed.): Practice guidelines for the treatment of people with psychiatric disorders. Washington: APA 2000; 413-96.

- Arzneimittelkommission der deutschen Ärzteschaft (AkdÄ): Empfehlungen zur Therapie der Depression (2nd ed.). Berlin: AkdÄ 2006. Arzneiverordnung in der Praxis; 33. http://www.akdae.de/Arzneimitteltherapie/TE/Archiv/Depression.pdf

- Canadian Psychiatric Association (CPA): Clinical guidelines for the treatment of depressive disorders. Can J Psychiatry 2001; 46 (Suppl 1): 5-90.

- De Jong-Meyer R, Hautzinger M, Kühner C, Schramm E: Evidenzbasierte Leitlinien zur Psychotherapie Affektiver Störungen. Göttingen: Hogrefe 2007.

- Deutsche Gesellschaft für Psychiatrie, Psychotherapie und Nervenheilkunde (DGPPN): Gaebel W, Falkai P (eds.): Praxisleitlinien in der Psychiatrie: Behandlungsleitline Affektive Erkrankungen. Darmstadt: Steinkopff 2000.

- Deutsche Gesellschaft für Psychotherapeutische Medizin (DGPM), Deutsche Gesellschaft für Psychoanalyse, Psychotherapie, Psychosomatik und Tiefenpsychologie (DGPT), Deutsches Kollegium Psychosomatische Medizin (DKPM), Allgemeine Ärztliche Gesellschaft für Psychotherapie (AÄGP): Psychotherapie der Depression 2002 [cited: 2007 Oct 17]. http://aerzteblatt.Insdata.de/download/files/2004/07/x0001045.pdf

- Härter M, Bermejo I, Schneider F, Kratz S, Gaebel W, Hegerl U, Berger M (eds.): Versorgungsleitlinien für depressive Störungen in der ambulanten Praxis. Z Arztl Fortbild Qualitatssich 2003; 97 (Suppl 4): 16-35. 